\title{
Correspondence
}

\section{Academies review insecticide harm}

The European Academies Science Advisory Council (EASAC) will next week release its report 'Ecosystem services, agriculture and neonicotinoids', which scrutinizes the scientific evidence for harmful effects by neonicotinoid insecticides. It concludes that widespread preventive use of neonicotinoids has adverse effects on non-target organisms that provide ecosystem services such as pollination and natural pest control.

The EASAC report goes beyond honeybees to include other valuable pollinators, such as bumblebees and solitary bees, and looks at ecosystem services that are crucial to sustainable agriculture. It is based on the findings of an international group of independent scientists, which I chaired, with expertise ranging from pollination biology through systems ecology to toxicology (see www.easac.eu).

The report points out that the preventive use of neonicotinoids is inconsistent with the principles of integrated pest management, as expressed in the European Union's (EU) sustainable pesticides directive. Such usage also constrains the potential for restoring farmland biodiversity under the $\mathrm{EU}$ agri-environment regulation. The group notes that neonicotinoids also have sublethal effects that need to be fully addressed in EU approval procedures.

The European Commission is due to review the effects of its 2013 restriction on the use of neonicotinoids on flowering crops. I believe that our report will help the European review to reassess the risk-benefit balance of neonicotinoid application. The wider risks to the environment and longer-term sustainability of agriculture must be considered alongside concerns that further restrictions could have shortterm implications for the economy and for food security. Peter Neumann Institute of
Bee Health, University of Bern, Switzerland.

peter.neumann@vetsuisse.unibe.ch

\section{Sanctions in Iran disrupt cancer care}

Economic sanctions against Iran have not formally targeted health care or access to drugs, but they have indirectly led to serious problems for health services notably for people with cancer.

Cancer is the third-highest cause of death in Iran, greater than in most other Middle Eastern countries. The Program of Action for Cancer Therapy, established by the International Atomic Energy Agency, evaluated the status of Iran's National Cancer Control Program (NCCP) in 2012. It concluded that the NCCP has substantial deficits in all aspects of care, including prevention, early detection, diagnosis, treatment, palliative care and monitoring technology (M. R. Rouhollahi et al. Arch. Iran Med. 17, 222-231; 2014). There is also a serious shortage of cancer drugs in the nation.

Sanctions disrupt health services and basic nutrition through complications in transportation, reduced imports, and difficulty in transferring hard currencies. There can be no improvement in the status of the NCCP until they are lifted. Shohreh Shahabi* Danbury Hospital, Connecticut; and Columbia University, USA. shohreh.shahabi@wchn.org ${ }^{\star}$ On behalf of 5 correspondents (see go.nature.com/gsdvk3 for full list).

\section{No case for Japan to kill minke whales}

On 12 April, an expert panel convened by the Scientific Committee of the International Whaling Commission (IWC) will deliver its review of Japan's latest proposal to kill Antarctic minke whales for research. Along with other members of the panel, I find that the Japanese government's scientific case does not justify lethal capture of any whales.

Japan's proposal to kill 333 whales every year until 2026 was submitted after the International Court of Justice ruled in March 2014 that the Japanese Whale Research Program under Special Permit in the Antarctic II (JARPA II) was not for purposes of scientific research. The court ordered Japan "to revoke any extant authorization, permit or licence to kill, take or treat whales in relation to JARPA II".

It is essential, therefore, that the review outcome is decisive and depends only on the quality of the scientific case for whaling made by Japan. This is implicit in the commission's new terms of reference (see IWC J. Cetacean Res. Manage. 16, S1-S5; 2015 and go.nature.com/j4dbeg).

Under these new terms, review panels are not required to make suggestions on how to improve proposals - but this historical practice still persists. I believe strongly that it must cease. It should not be assumed that whaling is inevitable (see P. J. Clapham Mar. Policy 51,238-241; 2015). Neither should panel members be made collaborators in an iterative approach towards approving whaling proposals. Otherwise, there is a risk that IWC practice as currently in effect could subvert the norm of independent review. Andrew S. Brierley University of St Andrews, UK. asb4@st-and.ac.uk

\section{One scientist's data as another's noise}

Reviewer Charles Seife considers my book Big Data, Little Data, No Data: Scholarship in the Networked World alongside two popular books on big data in commerce: Steve Lohr's Data-ism and Bruce Schneier's Data and Goliath (see Nature 518, 480-481; 2015). Yet the review does not make clear that mine is aimed at a very different audience.

I wrote the book for scientific researchers, scholars, librarians, publishers, policy-makers and other stakeholders, for whom the subtle uses of data as evidence in research are being swamped in the hype about big data. With case studies exploring how the idea of data varies in and between domains, I show how one researcher's data can be someone else's noise. Therein lies the rub.

Because so much about research data is open to personal interpretation, the information can be difficult to describe, represent and manage - and to share or reuse. The failure to understand these complexities leads to misguided policies for data management and to a lack of investment in both the workforce and the infrastructure for data curation. Ultimately, it can mean that no data survive for research.

Christine Borgman University of California, Los Angeles, USA. cborgman@g.ucla.edu

\section{Another two-body trick before Dawn}

You claim that NASA's Dawn probe is the first to have orbited two extraterrestrial bodies (Nature 519, 134; 2015), having arrived at the dwarf planet Ceres on 6 March after orbiting the asteroid Vesta in 2011-12 (see also Nature http://doi.org/287; 2015). But the Galileo mission to Jupiter had already accomplished the two-body trick.

Leaving aside a Copernican view that every space probe orbits the Sun even before launch, a gravity-assist trajectory passing Venus (once) and Earth (twice) put the Galileo craft in orbit around the Sun for more than three years. After heading to Jupiter, Galileo orbited it for almost eight years before plunging into the planet in 2003 to protect Jupiter's moon Europa from contamination.

John D. Rummel East Carolina University, Greenville, North Carolina, USA.

rummelj@ecu.edu 